\title{
Correction: Disparities in absolute cardiovascular risk, metabolic syndrome, hypertension, and other risk factors by income within racial/ethnic groups among middle-aged and older US people
}

Gulam Muhammed Al Kibria (D) - Reese Crispen • Muhammad Abdul Baker Chowdhury (D) Nadimpali Rao • Christina Stennett

Published online: 1 April 2021

(c) The Author(s), under exclusive licence to Springer Nature Limited 2021

Correction to: Journal of Human Hypertension

https://doi.org/10.1038/s41371-021-00513-8
Unfortunately, the spelling of the authors name Muhammad Abdul Baker Chowdhury was incorrect.

The original article has been corrected. 